\title{
Pequenas e grandes cidades turísticas do Nordeste: as diferenças na retomada do turismo no cenário pandêmico
}

Small and large tourist cities in the Northeast: the differences in the resumption of tourism in the pandemic scenario Pequeñas y grandes ciudades turísticas del Nordeste: las diferencias en la reanudación del turismo en el escenario pandémico

Carolina Todesco

Universidade Federal do Rio Grande do Norte (UFRN,

Brasil

caroltodesco@gmail.com

Maria Aparecida Pontes da Fonseca

Universidade Federal do Rio Grande do Norte (UFRN),

Brasil

mpontesfonseca@gmail.com

Itamara Lúcia Fonseca

Universidade Federal do Rio Grande do Norte (UFRN,

Brasil

itamaralfonseca@gmail.com
DOI: https://doi.org/10.18472/cvt.21n3.2021.1982 Redalyc: https://www.redalyc.org/articulo.oa? id $=115469516006$

Recepción: 01 Agosto 2021 Aprobación: 28 Octubre 2021

\section{Resumo:}

O presente estudo tem por objetivo analisar a retomada do turismo nas pequenas e grandes cidades turísticas do Nordeste durante a pandemia de Covid-19, em 2020. Como procedimento metodológico, foram explorados principalmente os dados de empregos do Novo Caged do Ministério da Economia e os dados da pesquisa de demanda turística do Grupo de Pesquisa Turismo em Tempos de Pandemia. A pesquisa revela que as pequenas cidades turísticas do Nordeste foram destinos desejados pelos turistas em busca de localidades menos urbanizadas, com menor incidência de óbitos por Covid-19, sem aglomerações e que adotaram medidas de biossegurança, colaborando para que algumas pequenas cidades tivessem, inclusive, saldo positivo de empregos no setor hoteleiro, em 2020, fato que não ocorreu em nenhuma grande cidade turística do Nordeste.

Palavras-chave: Covid-19, Turismo, Pequenas Cidades, Grandes Cidades.

\section{Abstract:}

This study aims to analyze the resumption of tourism in small and large tourist cities in the Northeast during the Covid-19 pandemic, in 2020. As a methodological procedure, mainly the employment data from the New Caged of the Ministry of Economy were explored and tourism demand survey data from the Tourism in Times of Pandemic Research Group. The research reveals that the small tourist cities in the Northeast were desired destinations by tourists in search of less urbanized locations, with a lower incidence of deaths by covid-19, without agglomerations and with biosafety measures, collaborating so that some small cities had a positive balance of jobs in the hotel sector, in 2020, a fact that did not occur in any large tourist city in the Northeast.

KeYWORDS: Covid-19, Tourism, Small cities, Major cities.

\section{RESUMEN:}

Este estudio tiene como objetivo analizar la reanudación del turismo en las pequeñas y grandes ciudades turísticas del Nordeste durante la pandemia del Covid-19, en 2020. Como procedimiento metodológico se exploraron principalmente los datos de empleo de Novo Caged del Ministerio de Economía y la encuesta de demanda turística. datos del Grupo de Investigación de Turismo en Tiempos de Pandemia. La investigación revela que las pequeñas ciudades turísticas del Nordeste fueron destinos deseados por turistas en busca de localidades menos urbanizadas, con menor incidencia de muertes por Covid-19, sin aglomeraciones y con 
medidas de bioseguridad, colaborando para que algunas ciudades pequeñas tuvieran un saldo positivo de puestos de trabajo en el sector hotelero, en 2020, hecho que no ocurrió en ninguna gran ciudad turística del Nordeste.

Palabras Clave: Covid-19, Turismo, Pequeñas ciudades, Grandes ciudade.

\section{INTRODUÇÃo}

Inúmeros estudos acadêmicos, órgãos oficiais e entidades de turismo nacionais e internacionais expuseram o desgaste que o setor de turismo sofrera com a pandemia de Covid-19, em 2020, especialmente devido às medidas restritivas de circulação de pessoas em diversas localidades do mundo (FGV, 2020; Cruz et al., 2021; Yang et al., 2020; Uğur et al., 2020; Brasil, 2020a, 2021; ONU News, 2020a, 2020b; WTTC, 2021).

Como em crises anteriores, a atual tem rebatimentos diferentes a depender do nível de vulnerabilidade socioeconômica em que se encontra cada porção do território, mas não apenas, pois por ser uma crise primeiramente de ordem sanitária, esta também afeta as localidades conforme as características da disseminação e evolução da doença, a suscetibilidade dos habitantes, a densidade demográfica e a configuração urbana (Viezzer; Biondi, 2021).

No decorrer do primeiro ano da pandemia, de março de 2020 a março de 2021, a região Nordeste do Brasil registrou 22,9\% dos casos e 21,5\% dos óbitos no país devido à Covid-19 (Kerr et al., 2021). No início da pandemia, conforme estudos de Kerr et al. (2021), todos os estados do Nordeste apresentaram um crescimento dos casos em seis semanas, primeiro nas capitais, depois no interior; nesse período, os governos estaduais e municipais nordestinos adotaram medidas intensas de isolamento. Essas medidas refrearam atividades que poderiam contribuir para a propagação da doença, dentre elas o turismo, que se configura como um importante setor econômico para muitas cidades, especialmente litorâneas, do Nordeste.

Essas medidas, no entanto, foram sendo reduzidas a partir do segundo semestre de 2020 (Kerr et al., 2021), e o turismo iniciou sua retomada, com cenas muito similares ao "velho" normal (Cruz, 2020). Nesse contexto, Todesco et al. (2021) observaram que a retomada das atividades características do turismo dos principais destinos litorâneos do Rio Grande do Norte apresentou, em termos relativos, melhor desempenho nas pequenas cidades comparado ao desempenho da capital, Natal. Tal constatação motivou a realização deste estudo, para verificar se esse padrão se repetiria nos demais estados nordestinos.

Assim, o presente trabalho tem por objetivo analisar a retomada do turismo nas pequenas e grandes cidades nordestinas, frente ao cenário pandêmico. $\mathrm{O}$ estudo parte da hipótese central de que os pequenos municípios turísticos, pelas suas características urbanas e populacionais, tornaram-se destinos mais desejados durante a pandemia e dessa forma tiveram uma perda relativa menor de empregos no setor, comparada a das grandes cidades.

A seguir, apresentamos as referências teóricas pertinentes às pequenas e grandes cidades, assim como uma breve discussão sobre a relação entre o urbano e a pandemia de Covid-19 e a retomada do turismo no Brasil. Posteriormente, detalhamos os procedimentos metodológicos, apresentando os critérios adotados para definir as pequenas e grandes cidades turísticas do Nordeste e as fontes dos dados exploradas para testar a hipótese da pesquisa. Em sequência, apresentamos os resultados sobre a pandemia de Covid-19 nas grandes e pequenas cidades selecionadas, o desempenho do mercado de trabalho do setor hoteleiro e os fatores de influência que motivaram as pessoas a viajar a lazer para o Nordeste durante a pandemia. Por fim, apresentamos nossas conclusões.

O estudo contribui para as reflexões acerca da retomada do turismo brasileiro diante da atual crise sanitária, que surpreendeu estudiosos, analistas e empresários da área pela rapidez com que tal fato ocorreu. 


\section{A relaÇÃo ENTRE A PANDEMIA de Covid-19 E A URBANIZAÇÃo}

\subsection{Grandes e pequenas cidades na hierarquia urbana brasileira}

No estudo publicado pelo IBGE (2020), "Região de Influência das cidades: 2018”, a rede urbana brasileira foi estruturada a partir de duas dimensões: a. através da "hierarquia dos centros urbanos", dividindo-se em cinco grandes níveis (1. Metrópoles; 2. Capitais Regionais; 3. Centros Sub-Regionais; 4. Centros de Zona; 5. Centros Locais); b. através das "regiões de influência", identificadas pela ligação das cidades na hierarquia urbana, sendo as metrópoles o elo final de cada rede.

No presente estudo, é avaliada a relação entre turismo e pandemia em municipios situados nas extremidades da rede urbana brasileira, ou seja, metrópoles, capitais regionais e centros locais. As metrópoles ocupam o primeiro nível hierárquico da rede urbana brasileira e exercem influência direta nas demais cidades, às vezes simultaneamente. As capitais regionais compõem o segundo nível hierárquico; nessa categoria encontram-se os centros urbanos com alta concentração de atividades de gestão, mas com alcance menor em termos de região de influência em relação às metrópoles, com a população variando entre 800 mil e 1,4 milhão de habitantes, em 2018. Os centros locais formam o quinto e último nível hierárquico da rede urbana, constituindo-se na grande maioria das cidades do país, totalizando 4.037 centros urbanos, com média populacional de 12,5 mil habitantes; polarizam apenas os limites territoriais do próprio município, com fraca centralidade de suas atividades empresariais e de gestão pública (IBGE, 2020).

Apesar da representatividade das pequenas cidades na realidade do país, Fresca (2010) observa que somente a partir da década de 1990 intensifica-se o número de trabalhos tendo as pequenas cidades como objeto de estudo, com especial foco na análise das redes urbanas regionais.

"A palavra pequena é um adjetivo, que remete à noção de tamanho, dimensão e, no caso das cidades, uma associação entre pequeno número de habitantes com pequena área” (Fresca 2010, p. 76). Para Corrêa (1999), as cidades pequenas são aquelas que possuem no máximo cinquenta mil habitantes. Porém, Fresca (2001, 2010), Corrêa (1999) e Fernandes (2018) consideram insuficiente utilizar somente os dados demográficos para definir uma cidade como pequena, pois corre-se o risco de igualar cidades que na sua essência são diferentes.

Assim, Fresca (2010) defende a inserção das cidades pequenas em redes urbanas como caminho profícuo ao seu entendimento. No mesmo sentido, Fernandes (2018) considera que a conceituação das pequenas cidades perpassa por abordagens quantitativas (os patamares mínimos e máximos de habitantes) e qualitativas (as relações e influências na rede urbana e a formação socioespacial das regiões).

Corrêa (1999) alerta para o fato de que a globalização refuncionaliza, em graus distintos, todos os centros das redes urbanas, e a refuncionalização das pequenas cidades também passa a se realizar por meio:

da transformação do pequeno núcleo a partir de novas atividades, induzidas de fora ou criadas internamente, que conferem uma especialização produtiva ao núcleo preexistentes, inserindo-o diferentemente na rede urbana, introduzindo nela uma mais complexa divisão territorial do trabalho. (Corrêa, 1999, p. 50).

Em nosso caso, interessa-nos analisar as pequenas cidades litorâneas nordestinas que têm como característica a especialização na área do turismo, onde essa atividade envolve significativa parcela da força de trabalho local, geração de renda e impostos, ou seja, pequenas cidades que se inserem na divisão territorial do trabalho pela função turística que desempenham e assim ocupam uma posição diferenciada na rede urbana regional. 


\subsection{O papel das cidades no processo de difusão da pandemia}

Nos primeiros meses da pandemia, conforme expõem Leiva et al. (2020), as grandes cidades se tornaram portas de entrada privilegiadas de contágio e de disseminação da Covid-19 pelo território. Nesse sentido, "trata-se de uma doença dos espaços de fluxos", pois, segundo Aguiar (2020, p. 52), "a questão não está apenas na aglomeração em espaços fixos, [...], mas sobretudo no rastro de contaminação (geralmente invisível) que as pessoas vão deixando em seus fluxos pelos espaços". No caso brasileiro, a primeira manifestação da Covid-19 foi detectada na maior metrópole do Brasil (São Paulo), disseminando-se rapidamente para todo o país. Segundo Sposito e Guimarães (2020) ${ }^{[1]}$, “os dados sobre a difusão da doença no país indicam que se trata de um modelo hierárquico, fortemente relacionado com as interações espaciais existentes na rede urbana brasileira".

Mas diferenças na velocidade de contágio são visíveis entre cidades, regiões e países, por diversos fatores: efetividade de políticas públicas; aspectos culturais e comportamentais; condições de saúde, saneamento e higiene; adensamento e distribuição espacial da população; timing do início da pandemia; contexto político; estrutura urbana e mobilidade; dentre outros (Leiva et al., 2020).

De acordo com estudos de Chen et al. (2020), as cidades grandes e de alta densidade, com altos fluxos inter e intracidades, têm mais dificuldades em conter a propagação da doença. Nesse contexto, muitos pesquisadores estão se esforçando para explorar a dinâmica da pandemia em áreas urbanas. Viezzer e Biondi (2021), por exemplo, investigaram se os parâmetros da Covid-19 são mais elevados em cidades com maior urbanização, piores condições socioeconômicas e menos vegetação, adotando como amostra 3.052 municípios localizados no bioma da Mata Atlântica brasileira. Fortes correlações foram encontradas entre casos de Covid-19 e urbanização, enquanto aspectos socioeconômicos e ecoambientais, embora tenham apresentado correlação mais fraca com a Covid-19, apresentaram relações significativas com os parâmetros de saúde da população.

Mas no Brasil, conforme destacam Kerr et al. (2021) e Hallal (2021), há um fator importante para compreender o alto número de casos e de mortes pela Covid-19: a conduta negacionista, irresponsável e omissa do Governo Federal, em especial do chefe de Estado, diante das medidas de enfrentamento da pandemia. Essa postura, segundo Hallal (2021), contribuiu para o descrédito em relação à necessidade de distanciamento social e para o desestímulo à vacinação. Nas grandes cidades do Nordeste, por exemplo, o índice de isolamento social permaneceu acima de 0,45 somente nos meses de abril, maio e junho de 2020, e caiu significativamente a partir de julho de 2020 (gráfico 1).

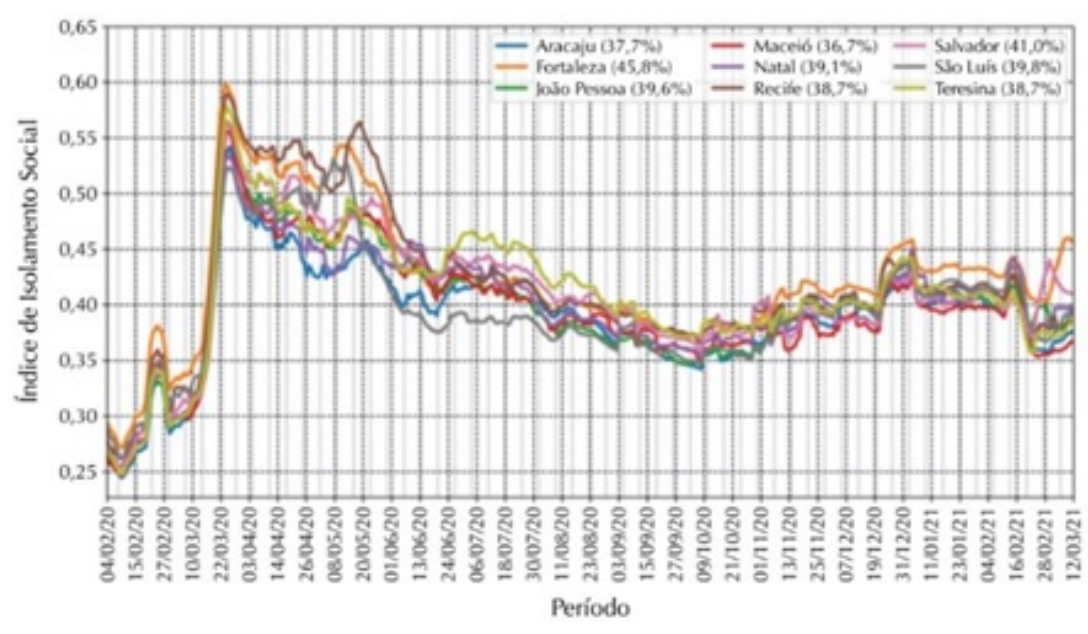

GRÁFICO 1

Índice de isolamento social das capitais nordestinas durante a pandemia Kerr et al. (2021). 
Para Kerr et al. (2021), a abertura da economia no segundo semestre de 2020, juntamente com as eleições e as festas de fim de ano, sem o acompanhamento de medidas não farmacêuticas de enfrentamento ao crescimento de casos, observados em muitas capitais e no interior do Nordeste, contribuíram para o quadro dramático vivenciado pela população nos meses iniciais de 2021. Além disso, o surgimento de uma nova variante viral do Sars-Cov-2, denominada P1, foi outro agravante que se impôs à pandemia no Brasil e no Nordeste.

Nesse cenário de agravantes, também se inclui a retomada do turismo no país, no segundo semestre de 2020, que apesar de ter sido um dos setores mais afetados em termos econômicos (gráfico 2), apresentou crescimento a partir do mês de julho, como se pode observar na movimentação de passageiros de voos domésticos nos aeroportos brasileiros (gráfico 3).

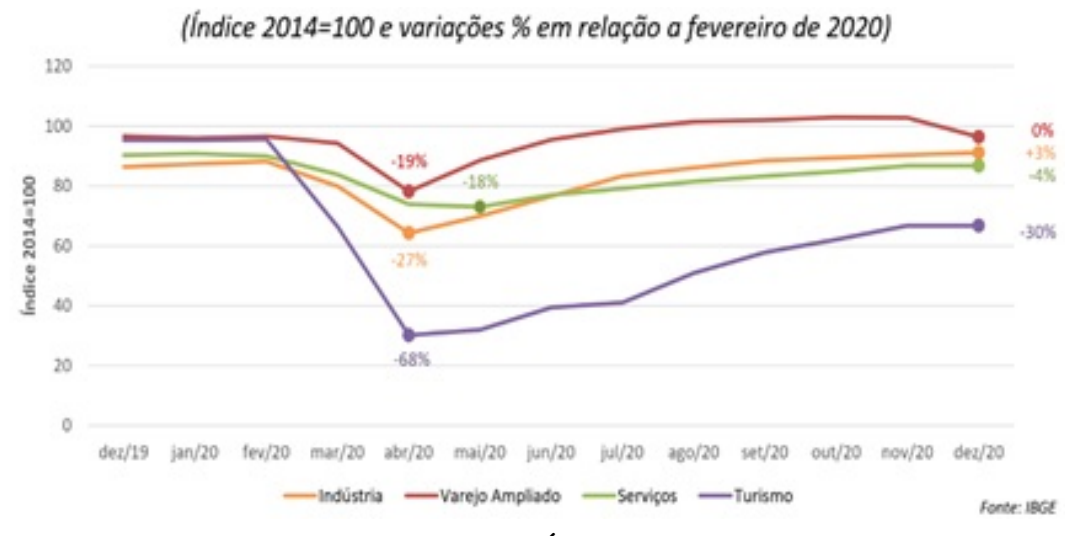

GRÁFICO 2

Indústria, comércio, serviços e turismo: níveis de atividade, em 2020, no Brasil CNC (2020).

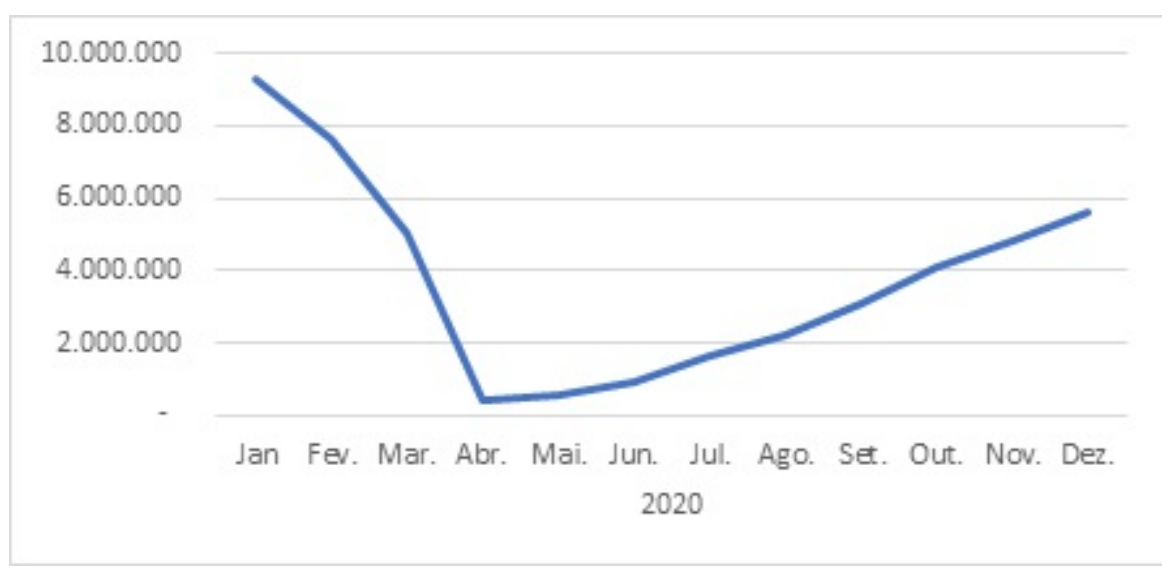

GRÁFICO 3

Número de passageiros de voos domésticos nos aeroportos brasileiros, em 2020 ANAC (2020). Organização própria.

Essa constatação suscitou, portanto, a intenção de investigar as possíveis diferenças na retomada do turismo no cenário pandêmico entre grandes e pequenas cidades, tendo em vista que tanto a pandemia de Covid-19 impôs novos comportamentos sociais (distanciamento físico, adoção de medidas de biossegurança), como também as cidades, a depender de suas características urbanas, se tornaram menos ou mais atrativas como destinos turísticos. 


\section{Metodologia}

As referências teóricas advindas da ciência geográfica, em especial de Corrêa (1999), Fresca (2010) e Fernandes (2018) acerca do conceito de pequenas e grandes cidades, foram importantes para subsidiar o recorte espacial da presente pesquisa, de caráter exploratória e explicativa, com abordagens quantitativas e qualitativas.

Para o recorte espacial do estudo, primeiramente foram selecionados os destinos turísticos da região Nordeste, tendo como base a categorização dos municípios do Mapa do Turismo Brasileiro, elaborado pelo Ministério do Turismo (Brasil, 2019). A partir do número de estabelecimentos e de empregos do setor de hospedagem, da estimativa de fluxo doméstico e internacional de turistas e dos impostos federais gerados pelo setor de hospedagem, o Ministério do Turismo atribui uma categoria aos municípios pertencentes às regiões turísticas, que varia de $\mathrm{A}$ até $\mathrm{E}$. $\mathrm{Na}$ pesquisa, foram priorizados os destinos turísticos classificados nas duas categorias mais elevadas, ou seja, A e B. Com tais critérios, foram identificados, na região Nordeste, 74 municípios, sendo que desses 11 são grandes cidades, incluindo as 9 capitais, e 23 são pequenas cidades, considerando, neste estudo, aquelas com menos de 50 mil habitantes (tabela 1).

TABELA 1

Número e porte dos municípios turísticos dos estados do Nordeste das categorias A e B

\begin{tabular}{lllll}
\hline U.F. & $\begin{array}{l}\text { Total de Municípios das } \\
\text { Categorias A e B }\end{array}$ & $\begin{array}{l}\text { Grandes } \\
\text { Cidades }\end{array}$ & $\begin{array}{l}\text { Pequenas } \\
\text { Cidades }\end{array}$ & $\begin{array}{l}\text { Médias } \\
\text { Cidade } \\
\text { s }\end{array}$ \\
\hline Alagoas & 4 & 1 & 2 & 1 \\
Bahia & 26 & 2 & 11 & 13 \\
Ceará & 14 & 1 & 3 & 10 \\
Sergipe & 1 & 1 & 0 & 0 \\
Rio Grande do Norte & 5 & 1 & 2 & 2 \\
Piaui & 3 & 1 & 1 & 1 \\
Pemambuco & 13 & 2 & 3 & 8 \\
Maranhão & 5 & 1 & 0 & 4 \\
Paraiba & 3 & 1 & 1 & 1 \\
Total & $\mathbf{7 4}$ & $\mathbf{1 1}$ & $\mathbf{2 3}$ & $\mathbf{4 0}$ \\
Total (\%) & $\mathbf{1 0 0 \%}$ & $\mathbf{1 5} \%$ & $\mathbf{3 1 \%}$ & $\mathbf{5 4 \%}$
\end{tabular}

Brasil, Ministério do Turismo, Categorização dos Municípios Turísticos, 2019. IBGE, cidades, população estimada, 2019. Nota: Grandes cidades = acima de 500 mil hab.; Médias cidades = entre 50 mil hab. a 500 mil hab.; Pequenas cidades = abaixo de 50 mil hab.

No segundo momento, foi feito um novo recorte na amostra, selecionando as capitais dos estados nordestinos (metrópoles e capital regional), na categoria de grandes cidades turísticas: São Luís/MA, Teresina/PI, Fortaleza/CE, Natal/RN, João Pessoa/PB, Maceió/AL, Recife/PE, Aracaju/SE e Salvador/BA; e até 2 pequenas cidades turísticas (centros locais), por estado: Luís Correa/PI, Jijoca de Jericoacora/CE, Beberibe/CE, Tibau do Sul/RN, São Miguel do Gostoso/RN, Conde/PB, Japaratinga/AL, Maragogi/AL, Fernando de Noronha/PE, Tamandaré/PE, Cairu/BA e Mata de São João/BA; totalizando 21 municípios (mapa 1), sendo apenas Teresina localizada no interior, enquanto todas as demais cidades são litorâneas. Nos estados da Bahia, Ceará e Pernambuco, que possuem mais de 2 pequenas cidades turísticas, foram selecionados os municípios com os maiores índices turísticos da categorização. 


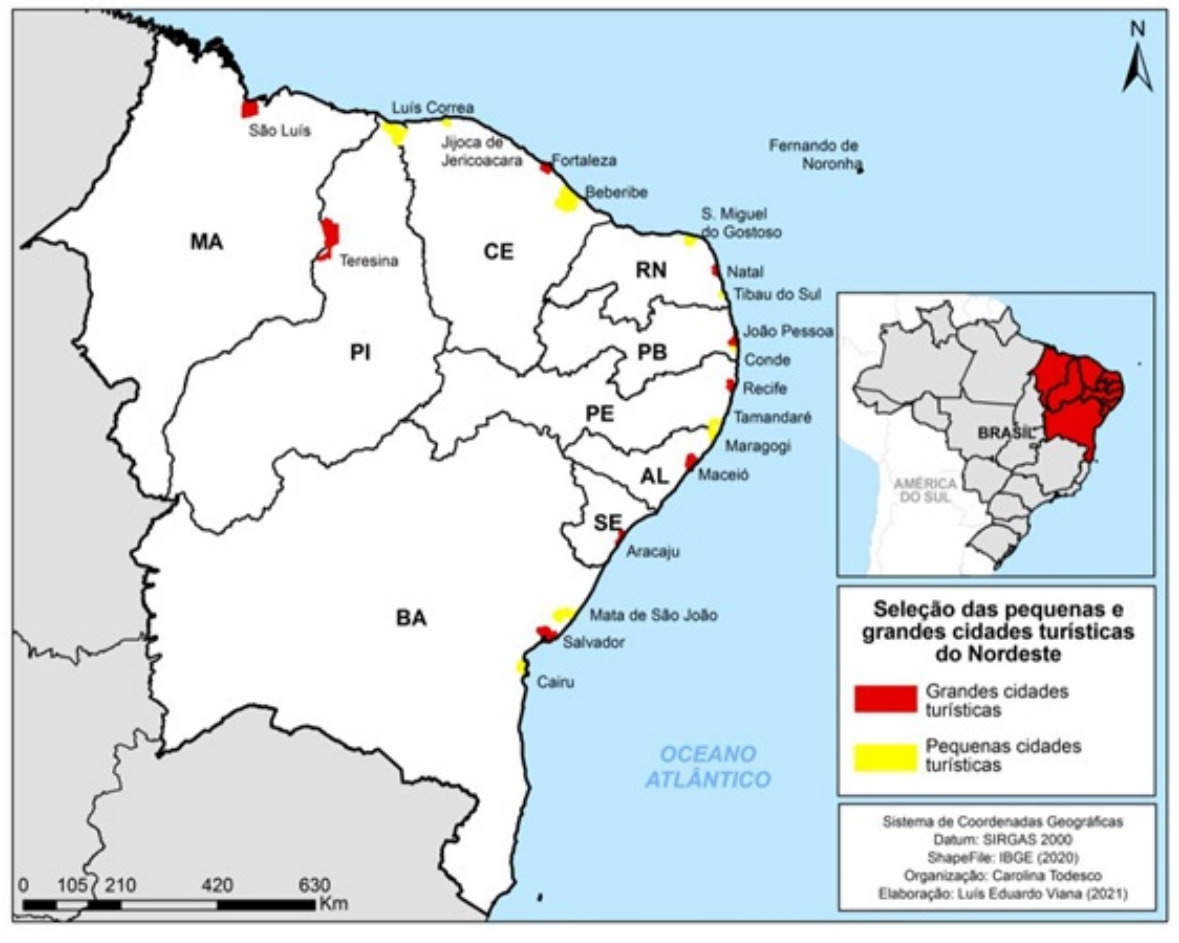

MAPA 1

Recorte espacial da pesquisa: grandes e pequenas cidades turísticas do Nordeste IBGE (2019)

Para a análise do desempenho do setor de turismo, foi selecionado, dentre as atividades características do turismo, aquela que, conforme estudos do IPEA (Sakowski, 2013), detém o maior coeficiente de empregos relacionado ao consumo dos turistas: o setor hoteleiro. Para o levantamento dos dados de emprego, foram coletados os dados de saldo de empregos mensais disponíveis no Novo Caged, do Ministério da Economia, selecionando a subclasse CNAE 2.0 - hotéis. Os dados das grandes e pequenas cidades foram analisados de forma comparativa, em termos relativos.

Para uma abordagem qualitativa, foi explorado o caso do Rio Grande do Norte, utilizando-se, dentre outras fontes, de entrevistas realizadas no mês de dezembro de 2020, por videoconferência, com secretárias municipais de turismo.

Além disso, para compreender os fatores de influência nas decisões de viagens a lazer ao Nordeste, foi utilizado o banco de dados da pesquisa realizada no âmbito do Grupo de Pesquisa Turismo em Tempos de Pandemia: uma análise multi e trans-escalar ${ }^{[2]}$. A pesquisa foi aplicada por meio do Google Forms, de forma não probabilística, por conveniência, com residentes no Brasil acima de 18 anos, totalizando uma amostra de 4.612 respondentes, com erro amostral de $2 \%$ e nível de confiança de $95 \%$.

\section{As PEQuenas E grandes CidAdes turísticas do Nordeste BRasileiro}

\subsection{Características populacionais e casos de Covid-19}

Uma das mais perceptíveis diferenças entre as pequenas e grandes cidades é exatamente a quantidade de habitantes. No caso dos municípios em estudo, verifica-se que as cidades mais populosas são as capitais Salvador/BA, Fortaleza/CE, e Recife/PE, que são metrópoles de mais 1,5 milhão de habitantes, porém, 
mesmo as capitais com menos de 1,5 milhão de habitantes apresentam uma alta densidade demográfica (tabela 2).

TABELA 2

Dados populacionais e mortes por Covid-19 nas pequenas e grandes cidades turísticas do Nordeste

\begin{tabular}{|c|c|c|c|c|c|c|}
\hline UF & Município & $\begin{array}{c}\text { Posição na hierarquia } \\
\text { urbana conforme o } \\
\text { IBGE } \\
\end{array}$ & $\begin{array}{c}\text { População } \\
\text { estimada } \\
2019 \\
\end{array}$ & $\begin{array}{c}\text { Densidade } \\
\text { demográfica } \\
\text { hab/km2 (2010) }\end{array}$ & $\begin{array}{c}\text { N. de óbitos } \\
\text { por Covid-19 } \\
\text { até jul. } 2021 \\
\end{array}$ & $\begin{array}{c}\text { Óbitos por } \\
\text { Covid-19 por } \\
100 \mathrm{k} \text { hab. }\end{array}$ \\
\hline \multicolumn{7}{|c|}{ PEQUENAS CIDADES } \\
\hline $\mathrm{AL}$ & Japaratinga & Centro-local & 8.361 & 90,22 & 14 & 166,61 \\
\hline $\mathrm{AL}$ & Maragogi & Centro-local & 32.704 & 86,06 & 46 & 139,26 \\
\hline $\mathrm{BA}$ & Cairu & Centro-local & 18.176 & 33,35 & 16 & 86,83 \\
\hline BA & Mata de São João & Centro-local & 46.583 & 63,46 & 61 & 129,44 \\
\hline $\mathrm{CE}$ & Jijoca de Jericoacoara & Centro-local & 19.816 & 83,02 & 29 & 144,37 \\
\hline $\mathrm{CE}$ & Beberibe & Centro-local & 53.573 & 30,37 & 110 & 203,9 \\
\hline PB & Conde & Centro-local & 24.670 & 123,74 & 42 & 167,93 \\
\hline $\mathrm{PE}$ & Fernando de Noronha & Centro-local & 3.061 & 154,55 & 2 & 64,5 \\
\hline $\mathrm{PE}$ & Tamandaré & Centro-local & 23.388 & 96,66 & 31 & 131,23 \\
\hline PI & Luís Correia & Centro-local & 30.311 & 26,52 & 61 & 200,41 \\
\hline & São Miguel do & Centro-local & & & & \\
\hline RN & Gostoso & & 10.282 & 25,22 & 17 & 164,06 \\
\hline $\mathrm{RN}$ & Tibau do Sul & Centro-local & 14.180 & 111,81 & 11 & 76,18 \\
\hline \multicolumn{7}{|c|}{ GRANDES CIDADES } \\
\hline & Salvador & Metrópole & 2.872 .347 & $3.859,44$ & 7.616 & 263,83 \\
\hline $\mathrm{CE}$ & Fortaleza & Metrópole & 2.669 .342 & $7.786,44$ & 9.374 & 348,92 \\
\hline $\mathrm{PE}$ & Recife & Metrópole & 1.645 .727 & $7.039,64$ & 4.865 & 294,23 \\
\hline $\mathrm{AL}$ & Maceió & Capital regional & 1.018 .948 & $1.854,10$ & 2.333 & 227,53 \\
\hline M & & Capital regional & & & & \\
\hline $\mathrm{A}$ & São Luís & & 1.101 .884 & $1.215,69$ & 2.461 & 221,92 \\
\hline PB & João Pessoa & Capital regional & 809.015 & $3.421,28$ & 2.833 & 346,54 \\
\hline PI & Teresina & Capital regional & 864.845 & 584,94 & 2.493 & 287,19 \\
\hline RN & Natal & Capital regional & 884.122 & $4.805,24$ & 2.585 & 290,29 \\
\hline $\mathrm{SE}$ & Aracaju & Capital regional & 657.013 & $3.140,65$ & 2.375 & 357,19 \\
\hline
\end{tabular}

IBGE cidades. Brasil.io, Especial covid-19: dados por município, 2021.

Enquanto as capitais possuem uma densidade demográfica que varia de 584,94 a $7.786,44 \mathrm{hab} / \mathrm{km}^{2}$, as pequenas cidades turísticas do Nordeste apresentam uma variação de 25,22 a $154,55 \mathrm{hab} / \mathrm{km}^{2}$. Fernando de Noronha/PE apresenta a maior densidade demográfica dentre os pequenos municípios, mas detém a menor população absoluta, apenas 3.061 hab. (IBGE, 2019). Essas características são importantes para compreender a complexidade de contenção da disseminação da Covid-19 nas cidades (Chen et al., 2020; Viezzer \& Biondi, 2021) e as repercussões da pandemia nesses destinos turísticos.

Como se pode observar na tabela 2, em termos absolutos e relativos, as pequenas cidades são as que apresentam os menores números de óbitos por Covid-19, considerando dados coletados até julho de 2021: Fernando de Noronha/PE contabilizou ao total 2 óbitos e o município que apresentou o maior número foi Beberibe/CE, com 110 óbitos. A relação de óbitos por $100 \mathrm{mil} / \mathrm{hab}$ varia de 64,5 a 200,41 nas cidades pequenas. Sendo que o município de Luís Correia/PI, que detém 200,41 óbitos por $100 \mathrm{mil} / \mathrm{hab}$, contabilizou ao total 61 mortes.

Por outro lado, todas as grandes cidades nordestinas ultrapassaram a marca de 2 mil mortes por Covid- 19 . Fortaleza atingiu 9.374 mortes, destacando-se em termos absolutos e relativos (348,92 óbitos por 100 mil/ hab). Dentre as capitais, São Luís é a que apresenta o menor número de óbitos por $100 \mathrm{mil} / \mathrm{hab}(221,92)$, mas se comparado às pequenas cidades é ainda superior. 


\subsection{O desempenho do setor hoteleiro no Nordeste durante o ano pandêmico de 2020}

Durante o ano de 2020, é perceptível a retomada do turismo no Nordeste, especificamente no segundo semestre, quando as medidas restritivas vão sendo substituídas pelos planos de retomada das atividades por parte dos governos estaduais e municipais. Esse cenário pode ser verificado com os dados de saldo mensal de empregos no setor de hospedagem. Conforme o gráfico 4, é possível identificar que praticamente todos os meios de hospedagem das pequenas e grandes cidades investigadas apresentaram uma queda significativa de empregos nos meses de março a junho de 2020, e mostraram saldos mensais positivos a partir de agosto, os quais permaneceram até o mês de fevereiro de 2021, e retornaram a cair no mês de março, em especial devido à segunda onda de Covid-19, que se apresentou mais letal que a primeira onda, exigindo novamente medidas restritivas.

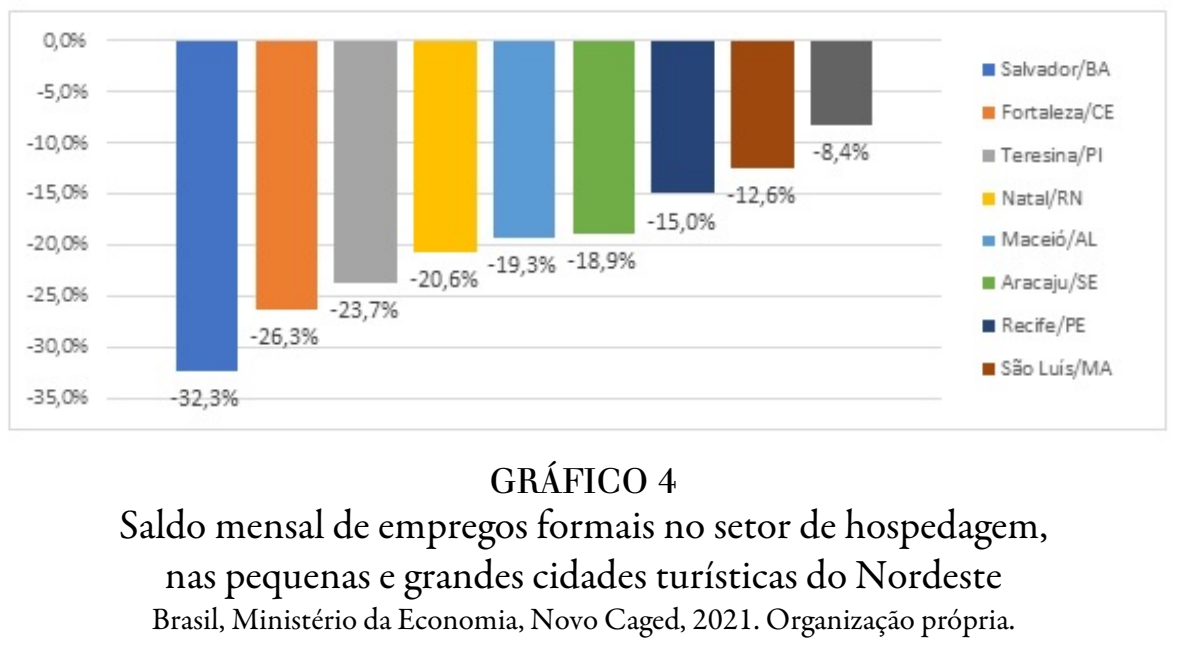

Em relação ao desempenho do setor hoteleiro durante o ano pandêmico de 2020, nota-se que, em termos relativos, as grandes cidades turísticas perderam mais postos de trabalho do que as pequenas cidades. Salvador/BA foi a cidade que apresentou a maior perda de postos de trabalho em hotéis, em comparação ao ano de 2019 (-32,3\%); em seguida vem a cidade de Fortaleza/CE (-26,3\%), Teresina/PI (-23,7\%) e Natal/ RN (-20,9\%). A capital que apresentou a menor perda foi João Pessoa/PB (-8,4\%), enquanto o pequeno município de Conde/PB atingiu um saldo positivo de 2,2\%. Verifica-se, portanto, que dentre os pequenos municípios turísticos as perdas foram menores, tendo alguns, inclusive, apresentado crescimento comparado com o ano de 2019. Identificou-se maiores perdas de postos de trabalho em hotéis em Cairu/BA e Mata de São João/BA, que registraram -19,6\% e -18,9\%, respectivamente, ambos localizados próximos à metrópole Salvador (mapa 1), que registrou uma perda muito superior (gráficos 5 e 6 ). 


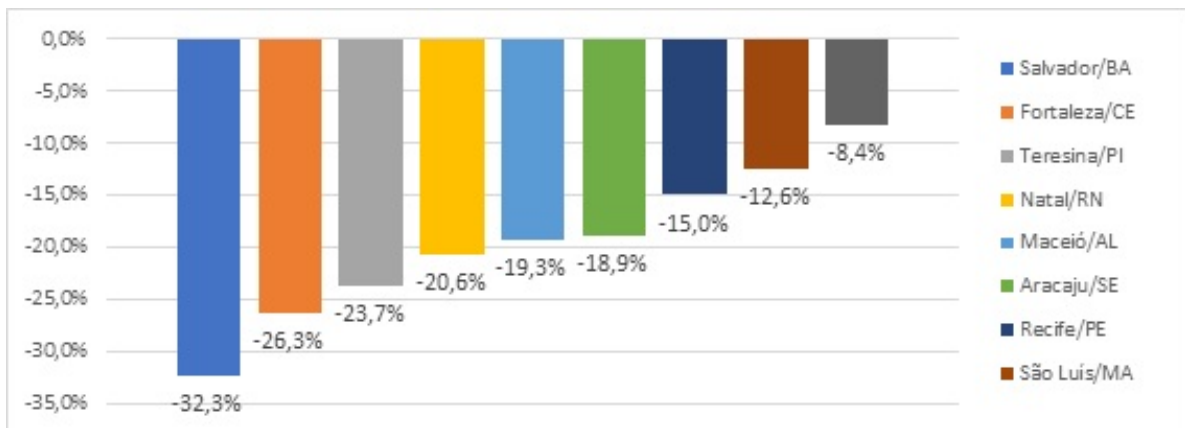

GRÁFICO 5

Variação percentual do número de postos de trabalho formal no setor de hospedagem, Brasil, Ministério da Economia, Novo Caged, 2020. Organização própria.

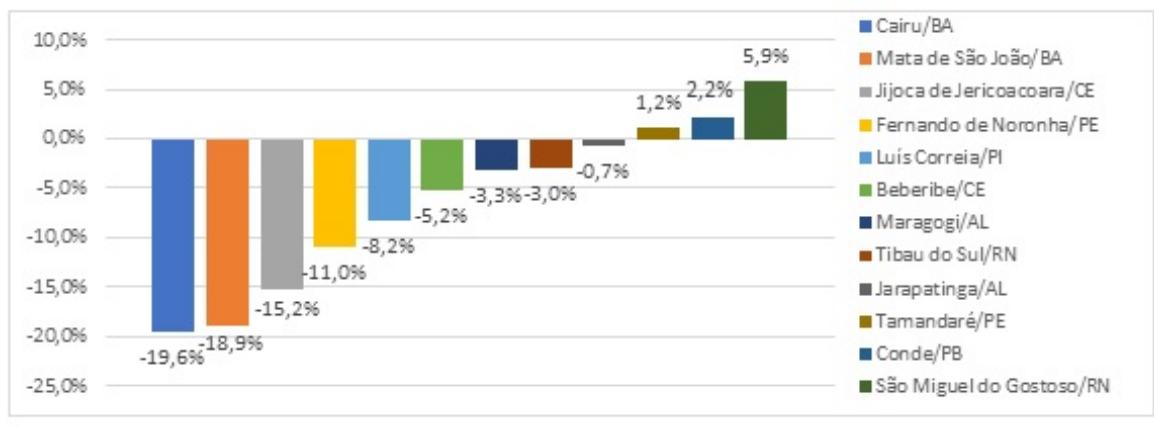

GRÁFICO 6

Variação percentual de número de postos de trabalho formal no setor de hospedagem, comparando o ano de 2019 e 2020, nas pequenas cidades turísticas do Nordeste Brasil, Ministério da Economia, Novo Caged, 2020. Organização própria.

Enquanto nenhuma capital apresentou saldo positivo ao final de 2020, comparado ao ano de 2019, entre as pequenas cidades se destacam São Miguel do Gostoso/RN, Conde/PB e Tamandaré/PE, que tiveram uma recuperação integral do número de empregos no setor hoteleiro e finalizaram o ano com um total acima de 2019 , em $5,9 \%, 2,2 \%$ e $1,2 \%$, respectivamente.

\subsection{Observando de perto o caso do Rio Grande do Norte: São Miguel do Gostoso, Tibau do Sul e Natal}

Como se pôde verificar, Natal/RN é a quarta capital nordestina com os piores índices de recuperação de emprego no setor hoteleiro, em 2020, enquanto São Miguel do Gostoso/RN e Tibau do Sul/RN estão entre as cinco pequenas cidades turísticas com o melhor resultado.

No contexto da pandemia, o governo estadual, por meio do "Plano de Retomada do Turismo do RN”, elaborado em maio de 2020, centrou esforços em estabelecer os protocolos de segurança e as medidas sanitárias para possibilitar o funcionamento adaptativo dos serviços turísticos. Reconhecido como o primeiro estado do Brasil a receber o selo internacional de turismo seguro (Safe Travel) pelo Conselho Mundial de Viagens e Turismo (WTTC) ${ }^{[3]}$, a Secretaria Estadual de Turismo e a Empresa Potiguar de Promoção Turística (Emprotur) passaram a trabalhar o reposicionamento do estado no mercado turístico, reconhecendo o turismo regional como âncora fundamental para impulsionar a retomada do setor e inspirar a confiança do turista a viajar para/pelo estado. 
Desse modo, a diversidade da oferta turística ganhou espaço nas campanhas promocionais da Emprotur, as quais também exploraram os atrativos de Tibau do Sul e São Miguel do Gostoso a partir do estereótipo de praias paradisíacas. A exemplo da campanha de promoção intitulada "Visite Rio Grande do Norte", os referidos municípios foram estrategicamente utilizados para divulgar o estado como o melhor e mais seguro destino de viagem do Nordeste (Panrotas, 2020).

Embora Natal tenha sido apontada pela pesquisa de Sondagem Empresarial do Ministério do Turismo (Brasil, 2020b) como principal destino de intenção de viagem em âmbito nacional no ano de 2020, a retomada do setor no estado tem dependido fortemente da oferta agregada de municípios próximos e do interior para impulsionar tal processo, uma vez que, segundo o levantamento do Sebrae/RN (2021), a tendência do setor no Rio Grande do Norte está voltada para destinos intermunicipais pela proximidade, visitados por meio de automóvel próprio, aspecto este endossado pela Fecomércio (2020), ao identificar que $50,2 \%$ dos turistas que visitaram o estado durante a alta estação de 2020/2021 utilizaram transporte próprio ou alugado.

Em entrevista cedida no mês de dezembro de 2020 pelas secretárias de turismo dos referidos municípios, Tibau do Sul e São Miguel do Gostoso, pode-se verificar a surpresa gerada pelo retorno do turismo, tanto pela rapidez, quanto pelo volume de turistas, como consta nos relatos a seguir:

A retomada do turismo em Tibau do Sul foi uma grande surpresa para todos. A partir de dia 8 de julho quando reabrimos oficialmente, nós estávamos com uma ocupação parcial dos hotéis de $60 \%$ e lotou de uma maneira que não esperávamos. O 7 de setembro foi o mais expressivo dos últimos 10 anos, e fomos obrigados a abrir 100\% dos hotéis, e digo que ultrapassou todos os réveillons que Pipa já teve. Inclusive, fomos reconhecidos pela WTTC como um destino seguro com os nossos protocolos e isso foi gerando uma segurança para o turista. (Secretária de Turismo de Tibau do Sul/RN, 2020) [4].

Em São Miguel do Gostoso o primeiro "boom" do turismo foi o dia dos pais. Foi quando nós sentimos que o ano ia ser diferente. Desde quando abrimos a cidade em julho de 2020 nós não tivemos nenhuma baixa, ficamos desesperados porque para você ter uma ideia na Praia de Tourinhos você andava quilômetros para poder estacionar. (Secretária de São Miguel do Gostoso/RN, 2020) ${ }^{[5] .}$

Já o turismo na capital, Natal, além de ser ancorado no turismo de sol e mar, sua rede hoteleira também depende do turismo de eventos e de negócios que contribui para amenizar a sazonalidade. Entretanto, para se ter ideia, o Centro de Convenções de Natal, administrado pela Emprotur, realizou 7 eventos em janeiro e 1 evento em novembro de 2020, totalizando 8 eventos no ano, enquanto em 2019 foram realizados 45 eventos $^{[6]}$. Apesar de carecer de dados mais específicos, é notório que o turismo de negócios e o turismo de eventos, importantes segmentos turísticos para as capitais nordestinas, não retomaram em 2020. As reuniões e eventos por videoconferência e outras plataformas digitais estão substituindo a necessidade da presença física das pessoas, situação potencializada pela pandemia.

Além disso, cabe destacar que os municípios de Tibau do Sul e de São Miguel do Gostoso apresentaram, de abril de 2020 a julho de 2021, um total de 11 e 17 mortes por Covid-19, respectivamente, enquanto a capital, Natal, registrou 2.585 óbitos (ver tabela 2). Esses números tornaram-se um fator de influência importante nas decisões de viagem do brasileiro, o que pode ter impactado na recuperação maior do setor de turismo das pequenas cidades, como veremos a seguir.

\subsection{Pesquisa de demanda turística: fatores de influência nas decisões de viajar a lazer para o Nordeste}

Na pesquisa sobre a demanda turística, realizada no âmbito do Grupo de Pesquisa Turismo em Tempos de Pandemia: uma análise multi e trans-escalar, verifica-se que dos 4.612 respondentes, 2.406 viajaram a lazer durante o período de abril de 2020 a fevereiro de 2021 , correspondendo a 52,2\%, o que significa que metade dos residentes no Brasil, acima de 18 anos, realizaram viagens a lazer durante a pandemia. Desses que viajaram 
a lazer, 957 realizaram ao menos uma viagem para a região Nordeste, correspondendo a 39,8\%, revelando que o Nordeste foi um dos principais destinos de viagem. Desse universo de 957 respondentes que viajaram a lazer para/pelo Nordeste, $59 \%$ eram oriundos da própria região, $16 \%$ eram procedentes da região Sudeste, $12 \%$ do Centro-Oeste, $12 \%$ do Norte e $2 \%$ da região Sul (gráfico 7 ). Esse dado demonstra que o turismo na região Nordeste retomou suas atividades principalmente com turistas da própria região.

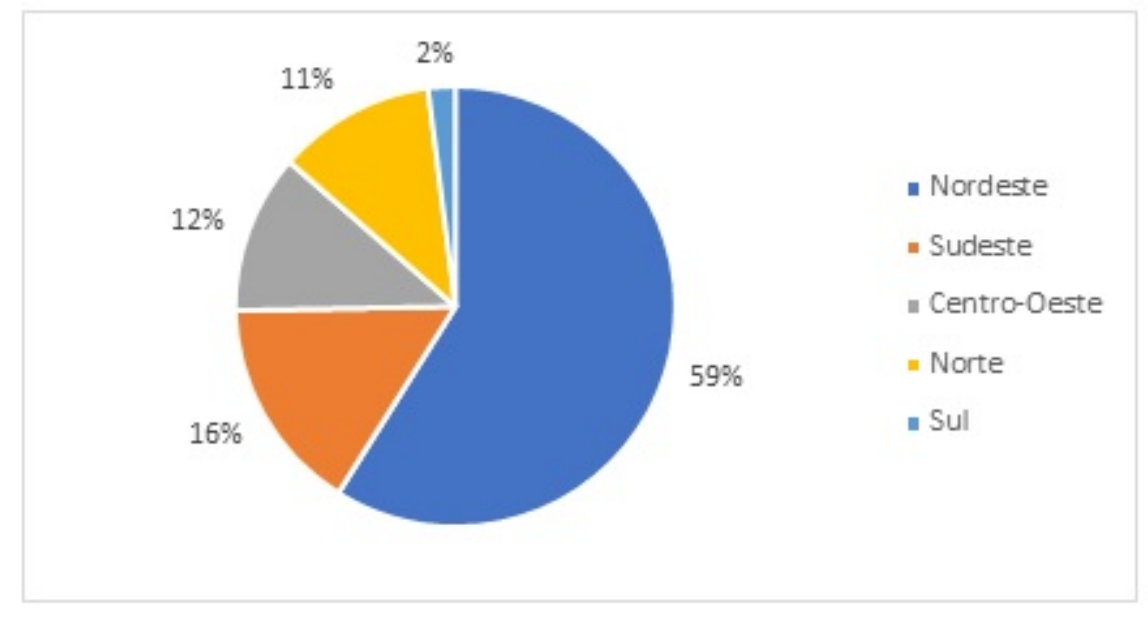

\section{GRÁFICO 7}

Região de origem dos turistas que viajaram a lazer para o Nordeste durante a pandemia Dados da pesquisa (2021). Elaboração própria.

Com o objetivo de identificar os fatores de influência nas decisões de viagens a lazer para o Nordeste, e testar nossa hipótese, foram selecionados dois grupos distintos para comparação: a. os que viajaram para as capitais; e b. os que viajaram para praias em áreas naturais; excluindo-se aqueles que viajaram para ambos os destinos.

O número de respondentes que viajaram para capitais totalizou 190 , correspondendo a $20 \%$, e os que viajaram para praias em áreas naturais totalizaram 371, equivalente a 39\% do total de turistas que viajaram a lazer pelo/para o Nordeste. A pesquisa mostra, portanto, que a porcentagem de turistas que procuraram praias em áreas naturais, ou seja, praias não urbanizadas, durante a pandemia foi muito superior à parcela de turistas que escolheu as grandes cidades turísticas do Nordeste.

Em relação aos fatores de influência nas decisões de viajar a lazer para destinos do Nordeste (tabela 3), a pesquisa revela que a maioria dos turistas que se dirigiu para praias em áreas naturais considerou determinante os três seguintes fatores: ausência de aglomeração nos destinos (59,3\%); baixa taxa de contágio e de mortes por Covid-19 no destino (51,5\%); e medidas de biossegurança nos destinos $(63,1 \%)$. Esses mesmos fatores não foram representativos para o grupo de turistas que se destinou para as capitais, tendo variado de $33,2 \%$ a $35,8 \%$. 
TABELA 3

Fatores de influência nas decisões de viajar a lazer para o Nordeste, considerando dois grupos de respondentes: turistas que se destinaram às capitais e turistas que se destinaram às praias naturais

\begin{tabular}{lcc}
\hline \multicolumn{3}{c}{ Ausência de aglomeração nos destinos } \\
\hline Níveis de Influência & Destino Capital & Destino Praia em Área Natural \\
Teve muita influência, foi determinante & $34,7 \%$ & $59,3 \%$ \\
Influenciou, mas não foi determinante & $27,9 \%$ & $25,6 \%$ \\
Não teve nenhuma influência & $28,9 \%$ & $10,0 \%$ \\
Não se aplica/Fator inexistente & $4,2 \%$ & $2,2 \%$ \\
Não sei responder & $4,2 \%$ & $3,0 \%$ \\
Total Geral & $100,0 \%$ & $100,0 \%$ \\
\hline
\end{tabular}

Baixa taxa de contágio e de mortes por Covid-19 no destino

\begin{tabular}{|c|c|c|}
\hline Níveis de Influência & Destino Capital & Destino Praia em Área Natural \\
\hline Teve muita influência, foi determinante & $33,2 \%$ & $51,5 \%$ \\
\hline Influenciou, mas não foi determinante & $28,4 \%$ & $28,8 \%$ \\
\hline Não teve nenhuma influência & $26,8 \%$ & $11,1 \%$ \\
\hline Não se aplica/Fator inexistente & $3,7 \%$ & $3,8 \%$ \\
\hline Não sei responder & $7,9 \%$ & $4,9 \%$ \\
\hline Total Geral & $100,0 \%$ & $100,0 \%$ \\
\hline \multicolumn{3}{|c|}{ Medidas de Biosegurança nos destinos } \\
\hline Níveis de Influência & Destino Capital & Destino Praia em Área Natural \\
\hline Teve muita influência, foi determinante & $35,8 \%$ & $63,1 \%$ \\
\hline Influenciou, mas não foi determinante & $38,4 \%$ & $25,1 \%$ \\
\hline Não teve nenhuma influência & $20,5 \%$ & $7,8 \%$ \\
\hline Não se aplica/Fator inexistente & $1,6 \%$ & $2,2 \%$ \\
\hline Não sei responder & $3,7 \%$ & $1,9 \%$ \\
\hline Total Geral & $100,0 \%$ & $100,0 \%$ \\
\hline
\end{tabular}

Dados da pesquisa (2021). Elaboração própria.

Verifica-se, portanto, que as pequenas cidades turísticas do Nordeste que integram a rede urbana regional e estão conectadas às regióes metropolitanas das respectivas capitais dos estados por meio de rodovias e aeroportos (Jijoca de Jericoacoara/CE e Fernando de Noronha/PE são as duas pequenas cidades turísticas que possuem aeroporto regional), conseguiram capitanear, mesmo em tempos de pandemia, os fluxos regionais, pelo fato de ter aumentado nesse período o turismo de proximidade, aquele realizado geralmente de carro próprio, num raio de $300 \mathrm{~km}$. Conforme a WTTC (2021, p. 16), "do ponto de vista da demanda, a Covid-19 está transformando as inclinações e os comportamentos dos viajantes em direção ao que é familiar, previsível, confiável e até mesmo de baixo risco". Mas as pequenas cidades turísticas do Nordeste também foram alvo de fluxos nacionais de turistas, oriundos das demais regiões brasileiras. Nota-se que esses fluxos regionais e nacionais que se destinaram às pequenas cidades turísticas nordestinas procuravam destinos menos urbanizados, menos populosos, sem aglomeraçóes e com menos casos de Covid-19. Atrelado a isso, destaca-se o papel das imagens promocionais das pequenas cidades turísticas (a título de exemplo, figura 1), que historicamente sempre exploraram a imagem de praia paradisíaca e deserta como principal cartão-postal (Araújo, 2017), mesmo quando na realidade essas praias são intensamente frequentadas. 

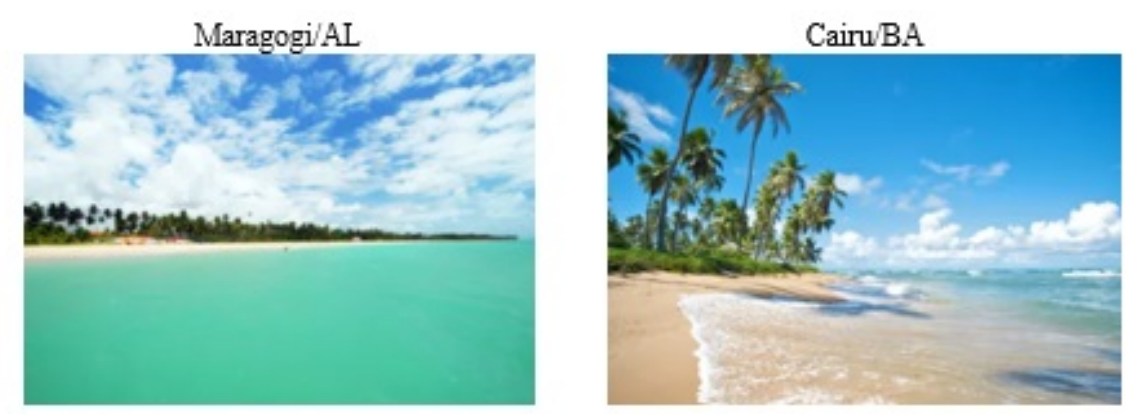

\section{FIGURA 1}

Imagens de duas pequenas cidades turísticas do Nordeste encontradas no site da CVC, maior operadora turística do Brasil Site oficial da CVC (https://www.cvc.com.br/destinos/). Acesso em: 21 jul. 2021

Assim, ocorre uma enorme contradição, pois os turistas, ao procurarem essas localidades por serem menos urbanizadas e povoadas, acabam gerando grandes aglomerações e sem as devidas medidas de biossegurança, o que é altamente contraindicado no contexto da pandemia, como se pode observar, por exemplo, na matéria de Erys e Rafael (2021), de 16 de fevereiro de 2021, intitulada "Cenário de aglomerações, Tibau do Sul tem crescimentos de $95 \%$ nos casos de Covid-19 em três meses”.

\section{ConsideraÇões Finais}

Os resultados encontrados contribuem para o entendimento da reação do turismo frente à crise sanitária, revelando diferenças espaciais importantes tanto no que diz respeito à incidência da Covid-19, como também na retomada da atividade turística no contexto das grandes e pequenas cidades nordestinas. Conforme discutido, alguns estudos apontam que a disseminação da Covid-19 ocorreu através dos meios de circulação, obedecendo à hierarquia da rede urbana. Assim, os centros locais alvos do estudo, situados no último lugar da hierarquia, mostraram-se menos afetados pela pandemia em termos de números de casos e mortes, e foram os lugares priorizados como destinos de viagens durante o período da crise sanitária.

Os turistas que viajaram para e pelo Nordeste brasileiro, buscando destinos sol-mar, privilegiaram localidades com menor incidência de casos da Covid-19, sem aglomeraçóes e que apresentavam uma predominância de paisagens naturais, isto é, menos urbanizadas. Tal fato impulsionou a retomada do turismo nos municípios de menor porte, sendo que alguns apresentaram, inclusive, saldo positivo de empregos no setor hoteleiro, em 2020, como foi o caso de São Miguel do Gostoso/RN, Conde/PB e Tamandaré/PE. Os demais tiveram perdas, no entanto, com índices bem inferiores aos das grandes cidades nordestinas.

O estudo, portanto, evidencia a força do turismo como uma prática socioespacial, pois mesmo no contexto da maior crise sanitária, as pessoas procuraram viajar, ainda que fosse para pequenas localidades. $\mathrm{O}$ isolamento social potencializou a necessidade desses deslocamento para o lazer e fruição, contribuindo, dessa forma, para a rápida retomada do turismo nas pequenas cidades, comparativamente aos grandes centros urbanos.

A busca pelas pequenas cidades turísticas por um grande contingente de pessoas provocou consideráveis aglomerações, especialmente em algumas datas específicas como finais de semana e feriados. Assim, ao atrair turistas pelo perfil de sua configuração urbana e pelas suas paisagens naturais, as pequenas cidades turísticas acabam se deparando com os desafios que os fluxos turísticos os impõem em tempos de pandemia, em especial, no controle da disseminação da doença e no gerenciamento e fiscalização da adoção das medidas protetivas e sanitárias por parte de empresas e turistas. 


\section{REFERÊNCIAS}

Aguiar, S. (2020). COVID-19: a doença dos espaços de fluxos. GEOgraphia, 22(48), 52-74.

ANAC. (2020). Base de dados estatísticos do transporte aéreo. https://www.anac.gov.br/assuntos/setor-regulado/emp resas/envio-de-informacoes/microdados.

Araújo, E. S. S. (2017). O Nordeste na promoção das operadoras de turismo. [Monografia de Graduação, Turismo/ UFRN]. Currais Novos, RN, Brasil.

Brasil, Ministério da Economia. (2020). Novo Caged. https://app.powerbi.com/view?r=eyJrIjoiNWI5NWI0ODEtY mZiYy00Mjg3LTkzNWUtY2UyYjIwMDE1YWI2IiwidCI6IjNIYzkyOTY5LTVhNTEtNGYxOC04YW M5LWVmOThmYmFmYTk3OCJ9

Brasil, Ministério do Turismo. (2019). Categorização dos municípios turisticos - 2019. http://turismo.gov.br/dadosab ertos/categorizacao/RELATORIO_CATEGORIZACAO_2019-Portal.xls.

Brasil, Ministério do Turismo. (2020a). Relatório de impacto da pandemia de Covid-19 nos setores de turismo e cultura no Brasil. http://www.dadosefatos.turismo.gov.br/boletins.html

Brasil. Ministério do Turismo. (2020b). Pesquisa de sondagem empresarial - 2020: empresários do setor de agências e organização de viagens no Brasil $2^{\circ}$ semestre de 2020. http://www.dadosefatos.turismo.gov.br/component/k2/i temlist/category/17.html.

Brasil, Ministério do Turismo. (2021). O impacto da pandemia de COVID-19 nos setores de Turismo e Cultura do Brasil. Dados e Informações do Turismo no Brasil, 1(2). http://dadosefatos.turismo.gov.br/revista.html

Brasil.io. (2021). Especial covid-19: dados por municipio. https://brasil.io/covid19/

Chen, J, Guo, X., Pan, H., Zhong, S. (2020). What determines city's resilience against epidemic outbreak: evidence from China's COVID-19 experience. Sustainable Cities and Society, 70, 1-11.

CNC. (2020). Setor mais afetado pela pandemia, turismo brasileiro perdeu 35,5 mil estabelecimentos em 2020.

Corrêa, R. L. (1999). Globalização e reestruturação da rede urbana: uma nota sobre as pequenas cidades. Território, 6, 43-53.

Cruz, R. C. A. (2020). Praias lotadas no feriado: o grito de independência de turistas pelo mundo e no Brasil. Le Monde Diplomatique Brasil, 14 set. 2020. https://diplomatique.org.br/o-grito-de-independencia-de-turistas-pelo-mun do-e-no-brasil/

Cruz, R. C. A., Silva, S. A., Larrabure, S. P., Todesco, C., Serra, H. R. H., \& Guambe, J. J. J. (2021). Turismo em tempos de Covid-19: ensaios sobre casos na Argentina, Brasil, Moçambique e Portugal. São Paulo: FFLCH/USP. http: //www.livrosabertos.sibi.usp.br/portaldelivrosUSP/catalog/book/627

Erys, L., \& Rafael, N. (2021). Cenário de aglomerações, Tibau do Sul tem crescimento de 95\% nos casos de Covid-19 em três meses. G1/RN Inter TV Cabugi, 16 fev. 2021. https://g1.globo.com/rn/rio-grande-do-norte/noticia/2021/02/16/cenario-de-aglomeracoes-tibau-do-s ul-tem-crescimento-de-95percent-nos-casos-de-covid-19-em-tres-meses.ghtml

Fecomércio/RN. (2020). Pesquisa da Fecomércio RN traça perfil do turista potiguar na alta estação 2020/2021. https: //fecomerciorn.com.br/wpcontent/uploads/2021/02/Infogra\%CC\%81fico_DEES_PerfilTurista.png

Fernandes, P. H. C. (2018). O urbano brasileiro a partir das pequenas cidades. Revista Eletrônica Geoaraguaia, Barra do Garças-MT, 8(1), 13-31. https://periodicoscientificos.ufmt.br/ojs/index.php/geo/article/view/6981

FGV. (2020). Impacto econômico do Covid-19 propostas para o turismo brasileiro. https://fgvprojetos.fgv.br/artigos/1a -edicao-impacto-economico-do-covid-19-propostas-para-o-turismo-brasileiro-abril-2020

Fresca, T. M. (2001). Em defesa dos estudos das cidades pequenas no ensino de geografia. Geografia, 10(1), 27-34.

Fresca, T. M. (2010). Centros locais e pequenas cidades: diferenças necessárias. Mercator, número especial, 75-81. ht tp://www.mercator.ufc.br/mercator/article/view/398

Hallal, P. C. (2021). SOS Brazil: science under attack. The Lancet, 397, 373-374. https://doi.org/10.1016/S0140-6 736(21)00141-0 
IBGE. (2020). Regiöes de influência das cidades 2018. https://www.ibge.gov.br/geociencias/organizacao-do-territorio /redes-e-fluxos-geograficos/15798-regioes-de-influencia-das-cidades.html

IBGE. (2019). Cidades. https://cidades.ibge.gov.br/

Kerr, et al. (2021). Covid-19 no Nordeste do Brasil: primeiro ano de pandemia e incertezas que estão por vir. Revista de Saúde Pública, 55(35). https://doi.org/10.11606/s1518-8787.2021055003728

Leiva, G. C., Sathler, D., \& Orrico Filho, R. D. (2020). Estrutura urbana e mobilidade populacional: implicações para o distanciamento social e disseminação da Covid-19. Revista Brasileira de Estudos de Populacão Rebep, 37, 1-22. http://dx.doi.org/10.20947/S0102-3098a0118

ONU NEWS. (2020a). Restriçôes de viagem afetam 96\% de todos os destinos mundiais. 18 abr. 2020.https://news.un .org/pt/story/2020/04/1710682.

ONU NEWS. (2020b). Pandemia transforma 2020 no pior ano para o setor de turismo internacional. 21 dez. 2020. 2020b. https://news.un.org/pt/story/2020/12/1736672

Panrotas. (2020). Bruno Reis detalha estratégia de retomada do Turismo no RN. https://www.panrotas.com.br/merca do/destinos/2020/07/bruno-reis-detalha-estrategia-de-retomada-do-turismo-no-rn_175386.html

Sakowski, P. A. M. (2013). Aspectos metodológicosdo sistema integrado de informações sobre o mercado de trabalho no setor turismo. Brasília: IPEA.

Sebrae/RN. (2021). Destinos locais $e$ atividades ao ar livre são tendências para $o$ turismo. https://www.sebrae.com.br/sites/asn/uf/NA/destinos-locais-e-atividades-ao-ar-livre-sao-tendenciaspara-o-turismo,75b0105627a3a710VgnVCM100000d701210aRCRD

Sposito, M. E. B., \& Guimarães, R. B. (2020). Por que a circulação de pessoas tem peso na difusão da pandemia. 26/03/2020. https://www2.unesp.br/sharer.php?noticia $=35626$

Todesco, C., Fonseca, M. A. P., Fonseca, I. L., \& Dantas, F. R. A. (2021). As repercurssões da pandemia de covid-19 no turismo dos principais destinos do Rio Grande do Norte. GeoUerj, 38. https://doi.org/10.12957/geouerj. 2021.61317

Uğur, N. G., \& Akbiyık, A. (2020). Impacts of COVID-19 on global tourism industry: A cross-regional comparison. Tourism Management Perspectives, 36. https://doi.org/10.1016/j.tmp.2020.100744

Viezzer, J., \& Biondi, D. (2021). The influence of urban, socio-economic, and eco-environmental aspects on COVID-19 cases, deaths and mortality: A multi-city case in the Atlantic Forest, Brazil. Sustainable Cities and Society, 69. https://doi.org/10.1016/j.scs.2021.102859

WTTC. (2020). Safe Travels global protocols \& stamps for the new normal. https://wttc.org/COVID-19/SafeTravel s-Global-Protocols-Stamp

WTTC. (2021). Global Economic Impact and Trends 2021. https://wttc.org/Portals/0/Documents/Reports/2021/ Global\%20Economic\%20Impact\%20and\%20Trends\%202021.pdf?ver=2021-07-01-114957-177

Yang, Y., Altschuler, B., Liang, Z., \& Li, Xiang. (2020). Monitoring the global COVID-19 impact on tourism: the COVID19 tourism index. Annals of Tourism Research. https://doi.org/10.1016/j.annals.2020.103120

\section{Notas}

1 Documento eletrônico não paginado.

2 O Grupo de Pesquisa Turismo em Tempos de Pandemia: uma análise multi e trans-escalar, cadastrado no CNPq, coordenado pela Profa. Dra. Rita de Cássia Ariza da Cruz, foi criado em maio de 2020 com o objetivo de analisar os impactos da pandemia no turismo em diferentes recortes espaciais. O Grupo conta com pesquisadores de cerca de 30 instituições de ensino superior nacionais e estrangeiras.

3 Conforme a WTTC (2020), o Selo Safe Travels foi criado para os viajantes reconhecerem destinos e empresas em todo o mundo que adotaram os protocolos padronizados globais de saúde e higiene, considerando as diretrizes da Organização Mundial da Saúde e do Centro de Controle e Prevenção de Doenças (CDC).

4 Entrevista realizada com a Secretária Municipal de Turismo de Tibau do Sul, por videoconferência, no dia 17 de dezembro de 2020. 
Carolina Todesco, et al. Pequenas e grandes cidades turísticas do Nordeste: as diferenças na retom...

5 Entrevista realizada com a Secretária Municipal de Turismo de São Miguel do Gostoso, por videoconferência, no dia 15 de dezembro de 2020.

6 Informação enviada pelo Setor Comercial do Centro de Convenções de Natal por correio eletrônico, no dia 05 de julho de 2021. 